\title{
How perceived uncertainties influence transitions; the case of micro-CHP in the Netherlands
}

\author{
Ineke S.M. Meijer $^{\mathrm{a}, \mathrm{b}, *}$, Marko P. Hekkert ${ }^{\mathrm{a}}$, Joop F.M. Koppenjan ${ }^{\mathrm{b}}$ \\ a Department of Innovation Studies, Copernicus Institute for Sustainable Development and Innovation, \\ Utrecht University, PO Box 80115, 3508 TC Utrecht, The Netherlands \\ b Department of Policy, Organisation and Management, Delft University of Technology, PO Box 5015, \\ 2600 GA Delft, The Netherlands
}

Received 23 March 2005; received in revised form 17 February 2006; accepted 23 February 2006

\begin{abstract}
Transitions, or socio-technological transformations, towards sustainability can be considered as a long-term transformation at the level of society as a whole, which in turn consists of a sequence of short-term innovations. The direction and speed of transitions are largely determined by the collective innovation decisions of various actors. A crucial characteristic of transitions is that they involve many uncertainties. The uncertainties that actors perceive greatly influence their innovation decisions. Namely, perceived uncertainties might stimulate some actors to fulfill certain key activities that are crucial for achieving a transition, while blocking other actors from undertaking these activities. In order to understand and manage transitions, insight into the types of perceived uncertainties that dominate the innovation decisions is essential. Furthermore, we need to understand if perceived uncertainties block or stimulate transitions by analyzing how actors respond to perceived uncertainties.

This article focuses on the first transition phase: the pre-development phase. An interesting case to study the role of uncertainties in this phase is the introduction of micro-CHP in the Netherlands. The main questions of this article are: Which types of perceived uncertainties are dominant for the innovation decisions related to micro-CHP in the Netherlands? How do actors react to the perceived uncertainties?

The case results demonstrate that different types of uncertainties influence the innovation decisions of the involved actors. The most dominant sources of uncertainty are technological and political uncertainty. Furthermore, the case shows that responses to uncertainty vary largely between various types of actors. Perceived
\end{abstract}

\footnotetext{
* Corresponding author. Tel.: +31 30253 1625; fax: +31 302532746 .

E-mail address: i.meijer@geo.uu.nl (I.S.M. Meijer).
} 
uncertainties seem to block some actors, but induce other actors in fulfilling key activities that are essential for achieving a transition. We discuss how these insights can be used for improving policy for stimulating transitions. (C) 2006 Elsevier Inc. All rights reserved.

Keywords: Perceived uncertainty; Transition; Innovation; Uncertainty management; Micro-CHP

\section{Introduction}

The concepts 'transition', 'socio-technological transformation' and 'system innovation' have been receiving much attention in literature [1-8]. Recently, a special issue of this journal was dedicated to these topics [9]. A transition, as we will call it in this article, is defined as a major, long-term technological change in the way societal functions (such as the supply of energy) are fulfilled [3,10]. Transitions that are initiated with a specific goal, such as the transition towards sustainability, are difficult to achieve $[1,3,9,11-15]$. Therefore, much research has been focusing on gaining insight into the characteristics of transitions and on applying these insights in the development of strategies and policies to steer such transitions (e.g. [5,9]). One of the outcomes of this research is that transitions have been characterized as consisting of several transition phases: pre-development, take-off, acceleration and stabilization [2,6]. This multi-phase conceptualization is helpful for analyzing transitions, but does not create insight in the underlying mechanisms that determine the dynamics of transition processes. In this article, we aim to contribute to a better understanding of these underlying mechanisms.

Starting point of this paper is that transitions are characterized by many uncertainties. These uncertainties play a key role, since they are considered to be one of the major blocking mechanisms of transitions $[1,15,16]$. Due to the long-time frame of transitions and the interrelatedness of technological and societal changes, uncertainty about the final outcome of a transition is large. Various types of involved actors each have their own vision of the future and these visions constantly change to adapt to new circumstances [6]. In order to reach each of the possible future outcomes, many separate innovation decisions (or 'transition steps') have to be taken [17]. It is the sum of these innovation decisions that leads to a transition. However, each of these innovation decisions is itself surrounded by uncertainties (e.g. [18-22]). The uncertainties that the involved actors perceive greatly influence their innovation decisions and thereby influence the transition as a whole. Thus, gaining insight in how perceived uncertainties influence innovation decisions and transition processes is important for better understanding the underlying mechanisms that determine transition processes.

Transitions involve a wide diversity of actors. While different actors each have their own perceptions of uncertainties, objectives and resources, they will also apply different strategies to cope with perceived uncertainties. One of the standard responses to perceived uncertainties is to delay or even to abandon (innovation) decisions [23]. In other words, perceived uncertainties might prevent actors from participating in transition steps. Participating in transition steps in this respect means that actors fulfill certain key activities that are essential for the success of a transition. For example, perceived uncertainties might prevent actors from investing in experiments. Since the final outcome of a transition is uncertain, it is essential for transitions that many of these experiments in various directions take place. Thus, perceived uncertainties can block the fulfillment of key activities and thereby hamper the overall transition [15]. However, perceived uncertainties do not necessarily have to hinder a transition. Some 
scholars argue that uncertainty is a precondition for innovation [24,25]. For instance, Jauch and Kraft (1986) argue that organizations in an uncertain environment tend to assume more risks and tend to be more proactive and innovative than organizations in a stable environment. Thus, instead of abandoning or delaying innovation decisions, actors can also accept that innovation is inherently uncertain and consciously deal with these uncertainties. To continue our example, perceived uncertainties can also form a driver for actors to undertake experiments in order to learn about the new technology and thereby reduce uncertainties. Thus, perceived uncertainties might also induce actors to fulfill certain activities that are essential for achieving a transition. In order to stimulate the transition towards a sustainable future, we therefore need to understand which uncertainties the involved actors perceive and whether or not actors' reactions to these uncertainties hamper the transition.

Although the importance of uncertainty in transition and innovation studies seems widely recognized (e.g. [1,18-22,24]), some authors argue that the concept of uncertainty is poorly worked out in innovation studies [26,27]. The aim of this article is to come to a better understanding of the underlying mechanisms of transition processes, by focusing on the influence of perceived uncertainties on innovation decisions. We build upon a previous article, in which the argumentation was made that the type of perceived uncertainties will vary depending on the transition phase and the type of actor [28]. In this article, we aim to elaborate on these theoretical notions and to apply the previously developed typology of uncertainty sources [28] to an empirical case. To keep research comprehensible, we thereby concentrate on only one transition phase: the pre-development phase. The empirical case focuses on an emerging technology that is currently in the pre-development phase, namely micro-CHP. Combined generation of heat and power (CHP), also known as cogeneration, means that electricity and heat are generated simultaneously. Up to now, CHP plants have been large-scale units used for industrial processes and district heating. Currently, progress is made to apply CHP at domestic scale (i.e. with an electrical power below $5 \mathrm{~kW}_{\mathrm{e}}$ ). This domestic application is called micro-CHP and is supposed to be a substitute for the high-efficiency boiler. The utilization of micro-CHP can lead to substantial energy savings and $\mathrm{CO}_{\mathrm{x}}$-emission reduction since the overall efficiency is higher compared to generating space heating, hot water and electricity separately and, due to the decentralized generation of electricity, distribution losses can be avoided. The development of micro-CHP in the Netherlands is an interesting case for studying the role of uncertainties in emerging transition technologies, since micro-CHP is considered as one of the promising innovations contributing to the transition towards a sustainable energy system and many activities are currently taking place around this technology. We pose the following research questions: Which types of perceived uncertainties are dominant for the innovation decisions related to micro-CHP in the Netherlands? How do actors react to the perceived uncertainties?

The methodology that we have applied for this research is outlined in Section 2. In Section 3, we describe the theoretical framework. The results of the empirical case are described in Section 4. We end our paper with the main conclusions and policy recommendations (Section 5).

\section{Methodology}

We have used a theoretical framework, described in Section 3, to study the relation between perceived uncertainties and actors' responses to these uncertainties. This framework was based on a review of uncertainty and innovation literature (see also [28]). The data for the empirical case was collected by reviewing grey literature (newspaper articles, professional journals and policy documents) and 
interviewing the main actors involved in the development of micro-CHP. Since micro-CHP is still in the pre-development phase, the number of involved actors, and consequently the number of interviews, is limited. We made a distinction between four groups of actors: technology-developers, potential adopters (i.e. buyers and users of the technology), intermediary organizations and governmental parties. We selected 10 interviewees who together form a good representation of the involved actor groups. All of the interviewees were well informed about micro-CHP, but not necessarily proponents of micro-CHP. We interviewed all technology-developers who are undertaking activities in the Netherlands. The group of potential adopters consisted of organizations that can play an important role in generating intermediary demand for micro-CHP (i.e. energy companies and housing organizations). We were unable to interview end-users (house owners or tenants), as they have not taken notice of micro-CHP yet. The government was represented by a spokesperson of the ministry of Economic Affairs, who was concerned with the energy (transition) policy. Furthermore, we interviewed an expert on micro-CHP of the key intermediary organization for CHP in the Netherlands (Cogen Projects). The interviews took place in the summer of 2004. We did a follow-up interview with the interviewee of the intermediary organization, in order to verify our conclusions and inquire about recent developments.

We started the interviews with a brainstorm question about perceptions of uncertainty. The answers to this question gave a good impression of the main uncertainties the interviewees perceived. In addition, this question served as a check to see if the uncertainties the interviewees mentioned corresponded with the typology of uncertainty sources used in the theoretical framework (see Section 3.1). In question 2, we introduced the typology of uncertainty sources and asked the interviewees to indicate if each of the sources was relevant for their innovation decisions and to give examples. In question 3, the interviewees were asked to rank the uncertainty sources according to their relative importance. Having identified the perceived uncertainties, we asked the interviewees which strategies they used for dealing with perceived uncertainties. In order to reduce the occurrence of strategically correct answers to this question, we verified the answers by reviewing grey literature on the strategies of the actors and by asking the interviewees not only about their own strategies, but also about the strategies of the other actors (triangulation). To prevent misinterpretations, all interviewees have reviewed the interview report. We have analyzed the interviews qualitatively.

\section{Uncertainty and transition}

In this section, we describe the theoretical framework that we use in this article to study the role of uncertainties in transitions. The theoretical framework consists of several parts. In Section 3.1, we introduce a typology of perceived uncertainties according to different uncertainty sources. Then (Section 3.2), we describe how actors can respond to perceived uncertainties, in terms of whether or not actors undertake certain key activities that are essential for achieving a transition. In Section 3.3, we discuss the role of uncertainties in the pre-development phase.

\subsection{Sources of perceived uncertainty}

In this article, the term 'uncertainty' is defined broadly as "any deviation from the unachievable ideal of completely deterministic knowledge of the relevant system" [29]. It is important to note that gathering information cannot always reduce uncertainty. Uncertainty can exist even in situations where much 
information is available [23,30]. In our terminology, uncertainty also relates to aspects that are by definition indeterminable, such as the behavior of other actors [23,31].

A continuing debate among scholars of uncertainty is the discussion about objective versus perceived uncertainty (e.g. [25,32]). Supporters of the objective view on uncertainty define uncertainty as a characteristic of the environment that can be measured objectively [33]. Supporters of the perceptive view on uncertainty argue that uncertainty is dependent on the individual and cannot be measured objectively [34]. The term 'perception' refers to the process by which individuals organize and evaluate stimuli from the environment. The existence of information itself lacks meaning until an individual perceives it [35]. Environments are therefore neither certain nor uncertain but are simply perceived differently by different actors. In this article, we are interested in the innovation behavior of actors. Namely, we want to analyze if uncertainties stimulate or block actors from fulfilling certain key activities that are essential for achieving a transition. Since perceived uncertainties, and not objective uncertainties, influence this behavior, we focus on 'perceived uncertainties'. In the remainder of this article, 'uncertainty' refers to 'perceived uncertainty'.

Having defined the concept 'perceived uncertainty', we can now introduce a typology of uncertainties. This typology is extensively described in [28]. We will classify perceived uncertainties according to their source. The source of uncertainty is the domain of the (organizational) environment, which the decision-maker is uncertain about [34]. Distinguishing between different sources of uncertainty is important for choosing appropriate strategies to cope with the uncertainty [36]. The six sources of perceived uncertainty with respect to innovation decision-making are [28]:

1. Technological uncertainty: This uncertainty source includes uncertainty about the characteristics of the new technology (such as costs or performance), uncertainty about the relation between the new technology and the infrastructure in which the technology is embedded (uncertainty to what extent adaptations to the infrastructure are needed) and uncertainty about the possibility of choosing alternative (future) technological options.

2. Resource uncertainty: Resource uncertainty is uncertainty about the amount and availability of raw material, human and financial resources needed for the innovation. Resource uncertainty also includes uncertainty about how to organize the innovation process (e.g. in-house or external R\&D, technologytransfer, educating personnel). Resource uncertainty both resides at the level of the individual firm, as well as at the level of the innovation system.

3. Competitive uncertainty: Whereas technological uncertainty includes uncertainty about competing technological options, competitive uncertainty relates to uncertainty about the behaviour of (potential or actual) competitors and the effects of this behaviour.

4. Supplier uncertainty: Uncertainty about the actions of suppliers amounts to uncertainty about timing, quality and price of the delivery. Supplier uncertainty becomes increasingly important when the dependence on a supplier is high.

5. Consumer uncertainty: Uncertainty about consumers relates to uncertainty about consumers' preferences with respect to the new technology, uncertainty about consumers' characteristics ${ }^{1}$ and, in general, uncertainty about the long-term development of the demand over time.

\footnotetext{
${ }^{1}$ For example, an important characteristic for energy technologies is the energy demand of consumers. Uncertainty about such characteristics can become a barrier in developing a product that is compatible with consumers' requirements.
} 
6. Political uncertainty: Political uncertainty comprises uncertainty about governmental behaviour, regimes and policies. Uncertainty can emerge about current policy (e.g. uncertainty about the interpretation or effect of policy, or uncertainty due to a lack of regulation) or about future changes in policy. Uncertainty about governmental behaviour (reliability of the government) is also an important cause for political uncertainty.

Since the technological development, the market and the networks of actors evolve in the subsequent transition phases, we expect that the dominance of the uncertainty sources will vary depending on the phase. Before we come back to this issue (in Section 3.3), we will look at how actors can respond to the uncertainties they perceive.

\subsection{Functioning of innovation systems}

Actors can respond to perceived uncertainties in many different ways. In this article, we are mainly interested in reactions to uncertainty that influence transitions. Therefore, we want to gain insight if perceived uncertainties stimulate or block the fulfillment of certain key activities that are essential for achieving a transition. Although each technological trajectory is unique with respect to the technological and institutional setting in which the transition takes place, the so-called 'innovation system, ${ }^{2}$ recent innovation scholars have formulated a generic list of key activities that contribute to the success of transitions. Since these key activities have the function to contribute to the goal of the innovation system, which is the generation, diffusion and utilization of innovations, the term 'functions of innovation systems' or 'system functions' is used to describe the set of key activities [37,38,15]. We distinguish the following system functions [38]:

1. Entrepreneurial activities: The role of an entrepreneur is to turn the potential of new knowledge development, networks and markets into concrete actions to generate and take advantage of business opportunities. Experimenting by entrepreneurs is necessary to collect more knowledge on the functioning of the technology under different circumstances and to evaluate reactions of consumers, government, suppliers and competitors.

2. Knowledge development: R\&D and knowledge development are prerequisites for innovation. This function encompasses 'learning by searching' and 'learning by doing'.

3. Knowledge diffusion through networks: The exchange of information through networks of actors (research institutes, governmental agencies, consumers, entrepreneurs) contributes to 'learning by interacting' and, in the case of user-producer networks, 'learning by using'. This function is especially important when a heterogeneous set of actors is involved in the innovation process.

4. Guidance of the search: Since resources are limited of nature, it is important that, when various technological options exist, specific foci are chosen for further investments. Without this selection, there will be insufficient resources for the individual options. This function includes those activities that can positively influence the visibility and clarity of specific needs among technology users.

\footnotetext{
${ }^{2}$ The concept of 'innovation system' is a heuristic attempt developed to analyze all such societal subsystems, actors and institutions contributing in one way or another, directly or indirectly, intentionally or not, to the emergence or production of innovation (Hekkert, Suurs et al., forthcoming).
} 
5. Market formation: New technologies often have difficulty competing with embedded technologies. Therefore, it is important to facilitate the formation of markets, e.g. by the formation of niche markets or by favorable tax regimes.

6. Resources mobilization: The allocation of sufficient resources, both human and financial, is necessary as a basic input to all the activities of the innovation process.

7. Creation of legitimacy/counteract the resistance to change: In order to develop well, new technologies often have to become part of an incumbent regime or even have to overthrow it. Parties with vested interest often oppose to this force of 'creative destruction'. In that case, advocacy coalitions can create legitimacy for the new technology by putting the new technology on the agenda and lobbying for resources and favorable tax regimes.

In this article, we use the term 'key activity' when we refer to the actor-level and the term '(system) function' when we refer to the system-level. If a system function is being fulfilled well, this means that actors have undertaken many key activities that contribute to this function. To illustrate, attending a conference or organizing a workshop are examples of key activities that an actor can undertake, which contribute to the function 'knowledge diffusion'.

According to this functional approach to innovation system policy, stimulating transitions implies stimulating the fulfillment of the aforementioned system functions [38,15,39]. Following Jacobsson and Bergek (2004), we add to this that uncertainties can be an underlying force that has a major influence on the functional pattern of innovation systems. Jacobsson and Bergek (2004) argue that high uncertainty in terms of technology, consumers and changing policy has blocked system fulfillment in the transition to renewable energy technologies. This would imply that policy aimed at stimulating transitions, should not only focus on the functions itself, but also take account of these uncertainties. If perceived uncertainties block the fulfillment of system functions, reducing the size of uncertainties or helping actors to cope with uncertainties may very well be an (indirect) way to stimulate desired functional patterns.

We expect that not only the dominance of the uncertainty sources, but also of the system functions will vary in different transition phases. In the next section, we take a closer look at the pre-development phase.

\subsection{Uncertainties in the pre-development phase}

This article focuses on the first transition phase: the pre-development or exploration phase.

\subsubsection{The actors}

The pre-development phase involves a wide variety of actors who each have their own objectives and play different roles in the transformation process. Because of these differences, we expect that various types of actors can have different perceptions of uncertainty. In other words, what is certain to one actor, does not have to be certain to another [40].

As a result of the differences in objectives, perceptions and roles of the actors, we furthermore expect that the reactions' to perceived uncertainties can differ between the various involved actors. Whereas some actors might react to perceived uncertainties by delaying actions, others will react by undertaking key activities, which contribute to the fulfillment of the system functions (see Section 3.2). What's more, distinguishing between the various types of actors helps to explain why some actors are more capable of undertaking certain key activities than others. For example, intermediary organizations will likely play 
an important role in fulfillment of the function 'knowledge diffusion', whereas technology-developers will likely be better in 'knowledge development'.

In short, we need to apply a multi-actor perspective in order to understand whether or not perceived uncertainties block the fulfillment of system function in the pre-development phase. Let us now describe some characteristics of this phase.

\subsubsection{The pre-development phase}

A new technological trajectory, and thus the pre-development phase, starts with the awareness that new directions are needed and new options and varieties emerge. This phase is characterized by basic $\mathrm{R} \& \mathrm{D}$ activities in which various routes and options are suggested and tried [2]. Technological variety is large since various technology-developers are working on competing products. These technological changes are interrelated to changes in the social dimension [3]. User needs co-evolve with technical possibilities and new industrial networks emerge around the new technology.

The appearance of the first working prototype serves as a 'proof of principal' and is a powerful final signal to other technology-developers that there will soon be a commercial product in the market [41]. The ability of a firm to progress faster than competitors along a technological trajectory is seen as a crucial element in this phase [41]. The pre-development phase ends when the first commercial product enters the market.

Based on these characteristics, we expect that some uncertainty sources will play a more important role than others in this phase. Below, we describe which uncertainty sources we expect to be dominant in the pre-development phase. We furthermore expect that these dominant uncertainty sources will influence the fulfillment of the system functions. Although Jacobsson and Bergek (2004) found empirical evidence that uncertainties can be an important blocking mechanism for the fulfillment of functions, how exactly these uncertainties influence the behavior of actors in terms of the system functions is still an under-researched topic. Therefore, we do not hypothesize over the relation between the uncertainties and the system functions.

\subsubsection{Dominant uncertainties}

In the pre-development phase, the search for new technologies is still very diffused and firms have no clear idea where to place their R\&D bets [42]. Therefore, we expect that technological uncertainty will play a dominant role in this phase. For potential adopters (consumers and buyers of the new technology), technological uncertainty will relate to questions like 'What can be expected of the new technology in terms of price, quality and other characteristics?'. For technology-developers, technological uncertainty relates to questions like 'Is it possible to develop a working prototype?', 'How will the technology function in real life situations?' and 'Are we searching in the right direction or should we choose a different technological trajectory?'.

We expect that uncertainty about the availability of resources to carry out the innovation process is also high in the pre-development phase. For technology-developers and potential adopters, resource uncertainty will relate to the question 'Which kind and which quantity of resources are necessary to develop or, respectively, to adopt, the new technology?'. Resource uncertainty not only resides at the

\footnotetext{
${ }^{3}$ Although there is a logical relation between the type of actors and the activities they perform, this is not a simple one-on-one relation. Namely, the activities of one actor can contribute to multiple system functions and, likewise, one system function can be performed by multiple actors.
} 
level of the individual firm, but also at the level of the innovation system. In this early phase, entrepreneurs will likely perceive uncertainty in not knowing what kinds of specialized competencies, basic knowledge or financial arrangements will emerge for the innovation at the system level [43]. Since the innovation has not yet entered the market, technology-developers have no revenues during this phase. Van de Ven et al. (1999) explain that start-up funding for a venture represents an initial stock of assets that provides the entrepreneur a 'honeymoon period' to develop and commercialize its innovation. However, interest and commitment wane with time. When the honeymoon period is over, many innovation efforts are terminated since the progress that is being made fails to live up to the expectations.

It is widely recognized that the emergence of a new technology is strongly influenced by the political climate (e.g. $[43,14,44])$.

Uncertainty if and how the government will support sustainable technologies like micro-CHP (e.g. uncertainty about acquiring subsidies, obstacles in regulation or political legitimacy for the new technology) can have a strong effect on the direction and speed of technology development. We therefore assume that political uncertainty will also play an important role in this phase.

Apart from technological, political and resource uncertainty, we furthermore expect that consumer uncertainty will play a dominant role in the pre-development phase. Since technological variety is still very large in this early phase and none of the prototypes is commercially available, consumers have difficulty in expressing their preferences and needs. Technology-developers will likely perceive uncertainty about which technologies will best satisfy consumers' preferences and needs and how large the potential market for their product will be. Potential consumers can themselves also perceive uncertainty about the emergence of a market for the new technology.

Although there might be some competition amongst technology-developers for who will be first in developing a successful prototype, uncertainty about the strategies of competitors will be less important for winning this R\&D race than uncertainty about the technology itself, consumers, resources and politics. Therefore, we expect that competitive uncertainty will only play a modest role in the predevelopment phase. We also expect that supplier uncertainty will hardly play a role in this phase, since dependence on suppliers raw materials or equipment will be low. In this early phase, manufacturing of the technology will take place at very small scale (in laboratories).

To conclude this theoretical section, in the empirical case, we aim to identify which uncertainty sources the various involved actors perceive and how these actors respond to the perceived uncertainties. By doing so, we aim to determine which uncertainty sources are perceived to dominate in the predevelopment phase and if these perceived uncertainties stimulate or block the fulfillment of system functions. We will formulate policy recommendations based on these insights.

\section{Uncertainties related to micro-CHP}

The case study that we discuss in this article is about the transition trajectory of micro-CHP in the Netherlands. Micro-CHP is the combined generation of heat and power at domestic scale (i.e. with an electrical power below $5 \mathrm{~kW}_{\mathrm{e}}$ ). We argue that micro-CHP is currently in the pre-development phase, because a working prototype has been developed but the first commercial product still has to enter the Dutch market.

In the Netherlands, the potential market for micro-CHP is high, as it is favored by the dense gas infrastructure, the relatively cool climate (temperate marine climate with cool summers and mild winters) 
and the tradition of decentralized cogeneration [45]. Since the utilization of micro-CHP can lead to substantial energy savings and $\mathrm{CO}_{\mathrm{x}}$-emission reduction, micro-CHP is seen as one of the promising technologies that can contribute to the energy transition. Within the framework of the Dutch 'energy transition policy', aimed at stimulating and managing the long-term transformation towards a sustainable energy system, much attention is being given to the application of micro-CHP $[1,46]$. Recently, market parties involved in this policy framework have initiated several experiments with micro-CHP systems. The goal of these experiments is to set the transformation process in motion and to demonstrate the possibilities of micro-CHP.

Micro-CHP systems can be based on several technologies. The most important competing technologies are the Stirling engine, the gas engine and the fuel cell. Most activities in the Netherlands focus on the Stirling engine and fuel cell technologies. The Stirling engine micro-CHP system appears to be the first micro-CHP technology that will enter the Dutch market. Due to the high heat/power ratio (low electrical efficiency and consequently higher heat production for a given capacity), the Stirling engine system is best suitable for dwellings with a relatively high heat demand. The fuel cell system has a high electrical efficiency and appears to be the most promising technology in the longer term. However, the fuel cell systems are still in an earlier stage of development and will need some more time before they are commercially available.

The first generation of micro-CHP systems is fuelled by natural gas and has a connection to the electricity grid. A connection to the grid is necessary, since the upcoming micro-CHP systems are dimensioned on the heat demand of the household. This means that the installation turns on when the household demands heat. Only then, the installation delivers electricity. Therefore, back-up electricity is needed. Connecting the micro-CHP system to the grid enables the household to import part of its electrical needs from the grid. In addition, the household may also export surplus electricity back to the grid when the heat demand is large and the electricity demand is low.

Research is being conducted into the application of micro-CHP systems as a 'virtual power plant'. The 'virtual power plant' implies that a multitude of micro-CHP units, which are dimensioned on the electricity demand, is controlled and managed from a central and remote location. In this way, the set of micro-CHP units operates as a distributed large power plant with great flexibility to meet peaking electricity demand in a specific region. Besides, research is taking place to the use of sustainable fuels (biogas or pure hydrogen) instead of natural gas to increase $\mathrm{CO}_{\mathrm{x}}$-emission reduction even more. These developments make micro-CHP suitable for various scenarios of the energy transition (such as the scenario of a hydrogen economy or a completely decentralized sustainable energy system).

Although micro-CHP is seen as a promising technology for achieving a transition in the energy system, the path towards large-scale application of micro-CHP is still long and there are many uncertainties on the way. In Section 4.1, we describe which of the uncertainty sources the various involved actors perceived to dominate their innovation decisions. Then (Section 4.2), we focus on how the actors reacted to these uncertainties.

\subsection{The dominant uncertainties}

In this section, we first give a general overview of the case-results by describing which uncertainty sources the various involved actors perceive as dominant. Then, we take a more detailed look at each of the dominant uncertainty sources. 
Table 1

Relative importance of uncertainty sources (interview question 3)

\begin{tabular}{|c|c|c|c|c|c|c|c|c|c|c|c|}
\hline & & \multicolumn{10}{|c|}{ Actors $\rightarrow$} \\
\hline & & TD1 & TD2 & TD3 & TD4 & A1 & A2 & A3 & A4 & $\mathrm{IO}$ & Gov \\
\hline \multirow[t]{6}{*}{ Ranking $\rightarrow$} & 1 & $\mathrm{P}$ & $\mathrm{T}$ & $\mathrm{T}$ & $\mathrm{T}$ & $\mathrm{Cs}$ & $\mathrm{Cs}$ & $\mathrm{T}$ & $\mathrm{P}$ & $\mathrm{T}$ & $\mathrm{Cs}$ \\
\hline & 2 & $\mathrm{Cs}$ & $\mathrm{S}$ & $\mathrm{P}$ & $\mathrm{P}$ & $\mathrm{T}$ & $\mathrm{T}$ & $\mathrm{P}$ & $\mathrm{T}$ & $\mathrm{P}$ & $\mathrm{R}$ \\
\hline & 3 & - & $\mathrm{P}$ & Cs & Other* & $\mathrm{P}$ & $\mathrm{S} / \mathrm{Cp}$ & $\mathrm{R}$ & - & $\mathrm{Cs}$ & - \\
\hline & 4 & - & $\mathrm{Cp}$ & $\mathrm{Cp}$ & - & $\mathrm{Cp}$ & $\mathrm{S} / \mathrm{Cp}$ & - & - & $\mathrm{Cp}$ & - \\
\hline & 5 & - & $\mathrm{R}$ & $\mathrm{R}$ & - & $\mathrm{R}$ & $\mathrm{P}$ & - & - & $\mathrm{S}$ & - \\
\hline & 6 & - & $\mathrm{Cs}$ & $\mathrm{S}$ & - & $\mathrm{S}$ & $\mathrm{R}$ & - & - & $\mathrm{R}$ & - \\
\hline
\end{tabular}

Ranking: $1=$ highest importance, $6=$ lowest importance.

Uncertainty sources: $\mathrm{P}=$ political, $\mathrm{Cs}=$ consumer, $\mathrm{Cp}=$ competitive, $\mathrm{R}=$ resource, $\mathrm{T}=$ technological, $\mathrm{S}=$ supplier.

Other* = uncertainty about the position of energy companies (especially with respect to energy company as 'owner/controller' of a group of micro-CHP systems).

Actors: $\mathrm{TD}=$ technology-developer, $\mathrm{A}=$ potential adopter (energy company or housing organization), Gov=government, namely ministry of Economic Affairs, $\mathrm{IO}=$ intermediary organization.

The empty cells mean that the other uncertainty sources are perceived equally important or not relevant (e.g. political uncertainty is not relevant for the government).

\subsubsection{The dominant uncertainty sources}

The interview results indicated that technological uncertainty and political uncertainty are the most dominant sources of uncertainty in the micro-CHP case, followed by consumer uncertainty. Table 1 shows the results of question 3, in which the interviewees had to rank the six uncertainty sources according to perceived importance. In this table, we can observe that technological uncertainty and political uncertainty scored overall highest on importance (highest number of 'rank 1' or 'rank 2' scores), followed by consumer uncertainty. Four interviewees clarified there ranking by stressing that technological uncertainty and political uncertainty were far more important than the other uncertainty sources.

The importance of technological and political uncertainty as observed in question 3, was confirmed by the answers to question 1 (brainstorm question ${ }^{4}$ ), since most of the uncertainties that the interviewees described related to technology or politics.

The many empty cells at the bottom of Table 1 indicate that the interviewees had difficulty ordering the relatively unimportant uncertainty sources. However, Table 1 does show that resource uncertainty scores relatively low. This was again confirmed by the answers to question 1 , since none of the answers to this question related to resource uncertainty.

The answer of the intermediary organization (IO in Table 1) should be interpreted slightly different. The intermediary organization did not rank the uncertainty sources according to uncertainties that were relevant for their own organization. Since this organization has a good overview of all the micro-CHP stakeholders, this interviewee ranked the uncertainty sources for the development of micro-CHP in general. Their ranking corresponded well to the answers of the overall importance of technological, political and consumer uncertainty.

The uncertainties that the government (Gov) perceived differ from the other actors (see Table 1). For the government, only two sources of uncertainty were relevant, namely consumer uncertainty and resource uncertainty. Government's decision to continue the experiments with micro-CHP within the

\footnotetext{
${ }^{4}$ See Section 2 for a description of the interview questions.
} 
'energy transition policy' framework was dependent upon the long-term prospects of micro-CHP. Consumer uncertainty and resource uncertainty both influence the long-term prospect of micro-CHP. The uncertainty about resources related to uncertainty whether technology-developers are able to upscale their production capacity. An even bigger uncertainty for the government was uncertainty about the creation of a market for micro-CHP in the Netherlands (e.g. how will the Dutch consumers react to micro-CHP and will the long-term demand for micro-CHP be large enough?) The other uncertainty sources were not relevant for governmental decision-making about micro-CHP (empty cells in Table 1).

To summarize the results so far, technological and political uncertainty seemed to be the most dominant uncertainty sources, followed by consumer uncertainty. The importance of technological uncertainty and political corresponded well to our expectations about the pre-development phase (see Section 3.3). However, resource uncertainty was overall perceived less important than we expected. Below, we will look at the uncertainty sources in more detail.

\subsubsection{Technological uncertainty}

The most important element of technological uncertainty was uncertainty about the technology itself, like: "How will micro-CHP systems perform in real-life situations?", "When will micro-CHP become a 'proven technology'?" or, more specific, "How will the (future) performance of micro-CHP systems be in terms of efficiency, investment cost, life span, maintenance, reliability, size and weight of the installation, level of noise, etc.?" This uncertainty was perceived equally important by all the actors (potential adopters as well as technology-developers) and for all the different micro-CHP technologies (since none of the technologies is yet a 'proven technology'). ${ }^{5}$

Uncertainty about the relation between micro-CHP and the technological infrastructure, another aspect of technological uncertainty, was perceived less important. Most of the interviewees did not foresee major technological difficulties connecting micro-CHP to the grid. Nevertheless, as we will describe below, the connection of micro-CHP to the grid does lead to substantial political uncertainties.

Uncertainty about alternative (future) technological options was also perceived less important in comparison to uncertainty about the technology itself. First of all, several interviewees explained that they cope with this uncertainty by keeping a number of options open instead of placing all their bets on one technology. This strategy seems logical for those actors that do not have a direct stake in the development of micro-CHP (like the potential adopters or the government). These actors can keep an eye open on various technologies without having to make large investments. However, also two technologydevelopers indicated that they keep several options open. To illustrate, one of them has performed pilot projects with both the Stirling engine and the fuel cell micro-CHP system and has also invested in R\&D projects with respect to the gas engine. Another explanation that was given for the small importance of uncertainty about alternative technologies was that each technology (different micro-CHP systems as well as other competing technologies like heat pumps) can occupy its own niche in the market. As a result of differences in heat/electricity performance between the different micro-CHP systems, one of the technology-developers believed that each technology has its own area of application.

\footnotetext{
${ }^{5}$ One technology-developer (TD1) currently only perceives uncertainty about two sources, namely politics and consumers. However, the other uncertainty sources did play a role when the company first considered investing in micro-CHP. At that time, technological uncertainty was perceived most important, followed subsequently by resource uncertainty, political uncertainty, supplier uncertainty, consumer uncertainty and, lowest importance, competitive uncertainty. The interviewee declares that most of the uncertainties have been resolved meanwhile.
} 


\subsubsection{Political uncertainty}

The other dominant source of uncertainty was political uncertainty. Many interviewees mentioned to be uncertain about the reliability of the government in general. Unexpected changes in policy, like the sudden ending of subsidy schemes for renewable energy, have led to a lack of faith in governmental policy and declining expectations about the new technology. This can be fatal for new technologies.

Not only uncertainty about subsidies, but also uncertainty about the energy taxes and electricity feedin policy strongly influences the economic feasibility of micro-CHP. In the current situation, micro-CHP owners pay energy taxes twice: first on the natural gas that they convert to electricity and second on the electricity that they temporarily 'store' on the grid (by feeding electricity in and at another moment retrieving the same quantity of electricity back). Furthermore, it is still uncertain which price micro-CHP owners will receive from the energy companies for the electricity they feed into the grid. ${ }^{6}$ Government regulation is necessary to solve this problem. At the moment of the interviews, this issue was still unsolved and proved to be a clear factor of uncertainty.

Other examples of political uncertainty were uncertainty about the incorporation and valuation of micro-CHP in energy saving norms, right of admission of micro-CHP installations to the grid and more general concerns on the vision of the Dutch government on sustainability and micro-CHP.

\subsubsection{Consumer uncertainty}

With respect to consumer uncertainty, we can see a clear distinction between the different types of actors. The technology-developers were hardly uncertain about the development of the market over time. They seemed convinced that there will be a market for micro-CHP systems. According to these actors, the emergence of a market is only a matter of time. Most of them claimed that uncertainties about the preferences or characteristics of consumers were small and could be reduced by market studies or pilot projects. Only one technology-developer (TD3 in Table 1) indicated that there were still major uncertainties about the market for micro-CHP. What is however striking is that this technologydeveloper deliberately ignored uncertainty about the market until the micro-CHP system will be ready for market introduction. Before then, the technology-developer focused only on managing technological and political uncertainty.

While the technology-developers seemed to have high expectations about the market for micro-CHP, the other actors (potential adopters, government and intermediary organization) were more restrained. These actors did perceive uncertainty about the development of a market, like how large and how fast this market will emerge. Two potential adopters (A1 and A2 in Table 1) even considered consumer uncertainty as the most important uncertainty source. They both explained that, if customers do not want micro-CHP, this will bring a stop to the entire development process. One of them argued that the lack of knowledge about micro-CHP among installation companies could become an important barrier for the market creation of micro-CHP. Installation companies need to be well-informed about micro-CHP, since they have to be able to install the micro-CHP systems and will only advise house owners to buy a micro-CHP

\footnotetext{
${ }^{6}$ For micro-CHP owners, an electricity feed-in price that is equal to the price a consumer pays for electricity (namely the commodity price, grid costs and energy taxes) would be most desirable. This equals that the electricity meter 'turns back' when electricity is feed into the grid. Energy companies, on the other hand, are not willing to pay back more than the commodity price. In the opinion of some energy companies, even a feed-in price equal to the commodity price of electricity would be too high since the supply of electricity produced with micro-CHP units creates more uncertainty for energy companies than electricity that they purchase or produce from large-scale production units.
} 
system if they know and positively value the technology. Most installation companies will not pay much attention to new technologies until they are commercially available. Two technology-developers (TD2 and TD3), the intermediary organization and the government, shared this uncertainty. ${ }^{7}$

\subsubsection{The remaining uncertainty sources}

The other uncertainty sources, namely uncertainty about suppliers, competitors and resources, only played a modest role in this case. The relatively minor importance of supplier and competitive uncertainty in this phase corresponded to our expectations (see Section 3.3), but resource uncertainty was less dominant than we expected. Overall, organizations that have a high stake in the development of micro-CHP (like micro-CHP developers) also seemed to be willing to allocate resources and therefore do not perceive uncertainty about resources. Only one technology-developer indicated that the availability of resources to continue their activities was a source of uncertainty. However, compared to the other sources of uncertainty, this source was relatively unimportant to the interviewee. The opposite reasoning holds as well: organizations that did not undertake many activities with respect to micro-CHP (like potential adopters) in this early phase did not need many resources and therefore did not perceive resource uncertainty. Two potential adopters explained that they only watched the course of events, but were unwilling to invest in micro-CHP as long as it is an unproven technology.

Likely, competitive, supplier and resource uncertainty will become more important in later phases. To illustrate this, one technology-developer (TD3) explained that in this phase the technology-developers still cooperate (e.g. in the micro-CHP working group which is led by the intermediary organization) in order to jointly accelerate the development process of micro-CHP, but that competition and competitive uncertainty will become more important when the micro-CHP systems enter the market. Supplier uncertainty might also become more important as the market introduction draws near, since technologydevelopers have to increase their production capacity. Two technology-developers (TD1 and TD2) were already trying to enter into cooperation agreements with suppliers in order to produce micro-CHP systems on a large-scale level. ${ }^{8}$ One of them perceived uncertainty about this.

\subsection{Managing uncertainties}

As we will illustrate below, the activities that the actors in the micro-CHP case undertook clearly focused on the uncertainty sources they perceived as dominant. Since the reactions to perceived uncertainties indeed varied between the different types of actor, we discuss which strategies were used to cope with perceived uncertainties for the different actor groups.

\subsubsection{Technology-developers}

Technology-developers consciously tried to deal with the uncertainties they perceived as dominant (i.e. technological and political uncertainty). In reaction to uncertainty about the (future) characteristics

\footnotetext{
${ }^{7}$ Installation companies play two roles: first, installation and maintenance of micro-CHP systems and, second, advising and selling micro-CHP systems to house owners (intermediate demand). According to the role, uncertainty about installation companies can either be seen as supplier uncertainty or as consumer uncertainty.

${ }^{8}$ Micro-CHP systems consist of a micro-CHP unit (Stirling engine, gas engine, fuel cell) in combination with a conventional condensing boiler (that supplies the peak load). Micro-CHP developers often depend upon suppliers for both the micro-CHP unit and the boiler in order to manufacture the micro-CHP system.
} 
of the technology, they all performed R\&D activities. These activities seemed successful, since progress has been made in terms of efficiency, reliability and life span of the micro-CHP systems, and the focus of the R\&D activities has been shifting more and more from basic R\&D towards making the product ready for market introduction. ${ }^{9}$ Thus, perceived technological uncertainty has induced these actors to undertake 'knowledge development' activities (function 2).

In reaction to perceived political uncertainty, the technology-developers undertook activities to create legitimacy for micro-CHP (function 7). The technology-developers cooperated with each other and with potential adopters in the micro-CHP working group that is led by the intermediary organization. This working group acts as an advocacy coalition, which aims to create legitimacy for micro-CHP by jointly lobbying for government support. Another example of an activity, which aimed at creating legitimacy for micro-CHP, was the demonstration project that one of the technology-developers initiated. The main goal of this project was to demonstrate that micro-CHP systems work in real-life situations ('proof of principal') and that the first commercial micro-CHP systems will soon enter the market. ${ }^{10}$ In short, for technology-developers perceived uncertainties induced function fulfillment.

\subsubsection{Potential adopters}

In comparison to technology-developers, the potential adopters were more passive in this phase. Their strategy can best be described as 'wait-and-see'. They did undertake some activities in order to stay informed about the developments of micro-CHP and to represent their interest, like participating in pilot projects and being member of the micro-CHP working group. However, they seemed unwilling to make large investments in micro-CHP while there are still major uncertainties. They have been delaying action until the uncertainties will be reduced by others (e.g. technology-developers) or by time. Thus, for these actors, perceived uncertainties seemed to block the fulfillment of system functions.

\subsubsection{Government}

The government has been stimulating the development of micro-CHP under the framework of the 'energy transition policy'. By expressing that micro-CHP is a promising technology and supporting experiments with micro-CHP, the government has helped to guide the direction of the search (function 4). A strong and visible preference of the government for micro-CHP can positively effect the R\&D priority setting and thereby might reduce uncertainty about the possibility of investing in different technological alternatives (i.e. technological uncertainty).

Guiding the direction of the search is, however, not enough. An important task of the government is to reduce political uncertainty. The lobby activities of the micro-CHP working group seemed to be effective, since the government was well informed about the political uncertainties that the micro-CHP stakeholders perceive. The government was aware of their task in reducing uncertainties about subsidies, admission to the grid, the electricity feed-in policy and energy taxes. Furthermore, the government endeavored to reduce uncertainty caused by unclear, inconsistent or a lack of regulation. For example,

\footnotetext{
${ }^{9}$ Recently (autumn 2005), we see that the activities of the technology-developers shifts more and more to creating a market for micro-CHP. For example, the technology-developers themselves and the micro-CHP working group are trying to involve installation companies and, meanwhile, several technology-developers have signed cooperation agreements with suppliers.

${ }^{10}$ Contrary to pilot projects, the primary goal of this demonstration project was not to test and improve the micro-CHP system. The micro-CHP system that was used for the demonstration project is not the system that the technology-developer is going to develop further into a commercial product.
} 
policymakers and policy-executors have been brought together (in a so-called 'service point') to collaborate on reducing ambiguities in legislation. However, the government argued that stakeholders should realize that uncertainty due to changes in policy is inevitable and that stakeholders should anticipate these changes instead of calling the government unreliable. The government felt that stakeholders sometimes incline to shift all the financial risk on to the government or even try to hinder competition by unjustly pleading for governmental intervention. The government has been trying to convince stakeholders to cooperate and deal with uncertainties collectively, instead of waiting for the government to reduce all uncertainties. This statement points out that there is a tension between the government and the micro-CHP stakeholders with respect to who should take the lead in bringing about the uncertain transformation towards sustainability.

\section{Conclusions}

The central questions we posed in this article were: Which types of perceived uncertainties are dominant for the innovation decisions related to micro-CHP in the Netherlands? and How do actors react to the perceived uncertainties?

We conclude that the two most dominant uncertainty sources in the pre-development phase of micro-CHP are technological uncertainty and political uncertainty, followed by consumer uncertainty. The importance of political and technological uncertainty corresponds well with our expectations about the pre-development phase (see Section 3.3), but resource uncertainty was perceived less important than we expected.

The case showed that perceived uncertainties play an important role in innovation and transition processes. Namely, perceived uncertainties influence the fulfillment of system functions that are essential for achieving a transition. However, the relation between perceived uncertainties and system functions is not straightforward, as the case showed that reactions to perceived uncertainties differ largely between the types of actors. Technology-developers, who all have a high stake in micro-CHP, consciously deal with uncertainties by undertaking all sorts of activities that contribute to the fulfillment of the system functions. The activities that these actors undertake clearly focus on the dominant uncertainty sources. In order to cope with technological uncertainty, technology-developers invest in knowledge development (function 2). In reaction to perceived uncertainties, technology-developers aim to create legitimacy for micro-CHP (function 7). Thus, perceived uncertainties form an incentive for technology-developers to fulfill key activities and thereby stimulate the transformation process as a whole. Potential adopters, on the other hand, seem to follow a 'wait-and-see' strategy. They seem unwilling to make large investments in micro-CHP while there are still major uncertainties. Although they participate in some of the activities (like participating in the micro-CHP working group and participating in pilot projects), they seem to wait until the dominant uncertainties have been resolved by the other actors. Thus, perceived uncertainties seem to block potential adopters to fulfill system functions. Yet, if we look at the different roles and positions of technology-developers and potential adopters, it is also logical that technology-developers are more active in fulfilling key activities in this pre-development phase than potential adopters.

The role of the Dutch government has been quite limited in this early transition phase. Governmental action has not been enough to reduce the political uncertainties that play such a dominant role in the micro-CHP case. Despite the perceived uncertainties and the limited governmental initiatives to reduce these uncertainties, the transition process was not hampered since technology-developers have been taking a leading role and are still making progress in the development of micro-CHP. However, we 
wonder if perceived uncertainties continue to induce the fulfillment of key activities in the following transition phases. The blocking effect of perceived uncertainties might increase once micro-CHP enters the take-off phase. For example, uncertainty about the electricity feed-in policy and energy taxes largely influences the economic feasibility of micro-CHP. If government still has not resolved this uncertainty once micro-CHP enters the take-off phase, this might become fatal for the emergence of a market. Thus, although the role of uncertainties in very early transition phases seems to be less crucial than in later phases, policymakers should start early with developing suitable instruments to reduce uncertainties or helping market parties in better coping with uncertainties.

Further research is needed into the role of perceived uncertainties in the following phases of the transformation process. It will be useful to compare the results of this case with cases that focus on different transition technologies. Continuing both empirical and theoretical work is necessary to deepen our insight into the role of uncertainties in transitions and how to manage these uncertainties.

\section{Acknowledgements}

This article is part of the research project 'Managing uncertainties in energy innovations and transition processes', financially supported by NWO (Dutch Organization for Scientific Research) and KSI (the Dutch Knowledge Network on System Innovations and Transitions). The authors would like to thank Margot van Gastel and the interviewees for their participation.

\section{References}

[1] J. Rotmans, Transitiemanagement: sleutel voor een duurzame samenleving, Assen: Koninklijke Van Gorcum (2003) 252.

[2] H. Van Lente, et al., Roles of strategic intermediaries in transition processes: the case of energy innovation systems, Int. J. Technol. Manag. 7 (3) (2003).

[3] F.W. Geels, Technological transitions as evolutionary reconfiguration processes: a multi-level perspective and a case-study, Res. Policy 31 (8-9) (2002) 1257-1274.

[4] F.W. Geels, Understanding the Dynamics of Technological Transitions : A Co-Evolutionary and Socio-Technical Analysis, in Centre for Studies of Science, Technology and Society, Twente University, Enschede, 2002.

[5] B. Elzen, F.W. Geels, K. Green, System Innovation and the Transition to Sustainability, Edward Elgar Publishing, Cheltenham, UK, 2004.

[6] J. Rotmans, R. Kemp, M.B.A. van Asselt, More evolution than revolution: transition management in public policy, Foresight 3 (1) (2001) 15-32.

[7] H.S. Brown, et al., Learning for sustainability transition through bounded socio-technical experiments in personal mobility, Technol. Anal. Strateg. Manag. 15 (3) (2003) 291-315.

[8] A. Smith, A. Stirling, F. Berkhout, The governance of sustainable socio-technical transitions, Res. Policy 34 (10) (2005) 1491-1510.

[9] B. Elzen, A. Wieczorek, Transitions towards sustainability through system innovation, Technol. Forecast. Soc. Change 72 (6) (2005) 651-661.

[10] F. Geels, R. Kemp, “Transities vanuit socio-technisch perspectief”; achtergronddocument bij hoofdstuk 1 van het rapport "Transities en transitiemanagement" (Rotmans et al, 2000). 2000, Merit (Universiteit Maastricht): Maastricht.

[11] A. Grubler, N. Nakicenovic, D.G. Victor, Modeling technological change: implications for the global environment, Annu. Rev. Energy Environ. 24 (1999) 545-569.

[12] S. Jacobsson, A. Johnson, The diffusion of renewable energy technology: an analytical framework and key issues for research, Energy Policy 28 (9) (2000) 625-640. 
[13] R. Kemp, L. Soete, The greening of technological-progress - an evolutionary perspective, Futures 24 (5) (1992) 437-457.

[14] G.C. Unruh, Understanding carbon lock-in, Energy Policy 28 (12) (2000) 817-830.

[15] S. Jacobsson, A. Bergek, Transforming the energy sector: the evolution of technological systems in renewable energy technology, Ind. Corp. Change 13 (5) (2004) 815-849.

[16] R. Kemp, J. Schot, R. Hoogma, Regime shifts to sustainability through processes of niche formation: the approach of strategic niche management, Technol. Anal. Strateg. Manag. 10 (2) (1998) 175-195.

[17] R.A.A. Suurs, et al., An actor oriented approach for assessing transition trajectories towards a sustainable energy system: an explorative case study on the Dutch transition to climate-neutral transport fuel chains, Innovat. Manag. Pol. Pract. 6 (2) (2004) 269-286.

[18] G. Dosi, Technological paradigms and technological trajectories: a suggested interpretation of the determinants and directions of technical change, Res. Policy 11 (1982) 147-162.

[19] C. Edquist (Ed.), Systems of Innovation; Technologies, Institutions and Organizations. Science, Technology and The International Political Economy Series, Pinter, London, 1997, 432 blz.

[20] C. Freeman, J. Clark, L. Soete, Unemployment and Technical Innovation: A Study of Long Waves and Economic Development, Pinter, London, 1982.

[21] R.R. Nelson, S.G. Winter, In search of useful theory of innovation, Res. Policy 6 (1) (1977) 36-76.

[22] R.E.H.M. Smits, S. Kuhlmann, The rise of systemic instruments in innovation policy, Int. J. Foresight Innov. Pol. (2004) $4-32$.

[23] J.F.M. Koppenjan, E.H. Klijn, Managing Uncertainties in Networks, Routledge, London, 2004.

[24] K.B. Clark, The interaction of design hierarchies and market concepts in technological evolution, Res. Policy 14 (5) (1985) 235-251.

[25] L.R. Jauch, K.L. Kraft, Strategic management of uncertainty, Acad. Manage. Rev. 11 (4) (1986) 777-790.

[26] L. Fleming, Recombinant uncertainty in technological search, Manage. Sci. 47 (1) (2001) 117-132.

[27] C.M. Corral, Environmental Policy and Technological Innovation: Why Do Firms Adopt or Reject New Technologies? (New Horizons in the Economics of Innovation Series), Edward Elgar, Northampton, MA, 2002.

[28] I.S.M. Meijer, et al., Perceived uncertainties regarding socio-technological transformation: towards a framework, Int. J. Foresight Innov. Pol. 2 (2) (2006) 214-240.

[29] W.E. Walker, et al., Defining uncertainty: a conceptual basis for uncertainty management in model-based decision support, Integr. Assess. 4 (1) (2003) 5-17.

[30] Van Asselt, M.B.A., Perspectives on Uncertainty and Risk, ed. I.I.C.f.I.S. Universiteit Maastricht. 2000, Dordrecht: Kluwer Academic Publishers.

[31] J.G. March, Decisions and Organizations, Basil Blackwell, Oxford, 1988.

[32] P. Kreiser, L. Marino, Analyzing the historical development of the environmental uncertainty construct, Manage. Decis. 40 (9) (2002) 895-905.

[33] G.G. Dess, D.W. Beard, Dimensions of organizational task environments, Adm. Sci. Q. 29 (1) (1984) $52-73$.

[34] F. Milliken, Three types of perceived uncertainty about the environment: state, effect, and response uncertainty, Acad. Manage. Rev. 12 (1) (1987) 133-143.

[35] H.L. Corrêa, Linking Flexibility, Uncertainty and Variability in Manufacturing Systems: Managing Un-Planned Change in the Automotive Industry, Aldershot, Avebury, 1994.

[36] B. Wernerfelt, A. Karnani, Competitive strategy under uncertainty, Strateg. Manage. J. 8 (2) (1987) 187-194.

[37] A. Johnson, Functions in Innovation System Approaches. In DRUID's Nelson-Winter Conference, 2001 Aalborg, Denmark.

[38] M.P. Hekkert, et al., Functions of innovation systems: a new approach for analysing technological change. Technological Forecasting \& Social Change, in press.

[39] S. Jacobsson, Formation and growth of sectoral innovation systems - 'functional analysis' as a tool for policy makers in identifying policy issues, RIDE, IMIT and Environmental Systems Analysis, Chalmers University of Technology: Gothenburg, Sweden, 2005.

[40] A.S. Huff, Consensual uncertainty, Acad. Manage. Rev. 3 (3) (1978) 651-655.

[41] F.F. Suarez, Battles for technological dominance: an integrative framework, Res. Policy 33 (2) (2004) 271-286.

[42] J.M. Utterback, Mastering the Dynamics of Innovation, Harvard Business School Press, Cambridge, 1994.

[43] A.H. Van de Ven, et al., The Innovation Journey, Oxford University Press, New York, 1999.

[44] A.A. Marcus, Policy uncertainty and technological innovation, Acad. Manage. Rev. 6 (3) (1981) 443-448. 
[45] M.D. d'Accadia, et al., Micro-combined heat and power in residential and light commercial applications, Appl. Therm. Eng. 23 (10) (2003) 1247-1259.

[46] Ministerie van EZ. Website Energietransitie, thema Nieuw Gas [website] 2006 [cited 200615 February]; Available from: www.energietransitie.nl.

Drs. Ineke S.M. Meijer (1979) is a PhD candidate at Utrecht University (Department of Innovation Studies, Copernicus Institute for Sustainable Development and Innovation) and Delft University of Technology (Department of Policy, Organisation and Management) in The Netherlands.

Dr. Marko P. Hekkert (1971) is Associate Professor of Sustainable Innovation at the Department of Innovation Studies, Copernicus Institute for Sustainable Development and Innovation, Utrecht University in The Netherlands.

Dr. Joop F.M. Koppenjan (1955) is Associate Professor within the Department of Policy, Organisation and Management, Faculty of Technology, Policy and Management of the Delft University of Technology. 